\title{
Inhibition of self pollen germination in Senecio vulgaris L.
}

\author{
J. M. Warren, \\ T. J. Crawford and \\ G. S. Oxford
}

Department of Biology, University of York, York YO1 5DD, U.K.

Experiments are described which show that Senecio vulgaris $\mathrm{L}$. (common groundsel) possesses two independent systems which inhibit the germination of self pollen. In one system, self but not cross pollen tube penetration of the stigma is prevented in the ray florets of a proportion of radiate plants. In the other system, cross pollen adheres in greater quantity than self pollen 24 hours after application to disc floret stigmas of both radiate and non-radiate plants. The possible origins of these systems, and their functions in natural populations, are discussed.

\section{INTRODUCTION}

Common groundsel, Senecio vulgaris L., is polymorphic for capitulum type (radiate and nonradiate) in many natural populations. The radiate morph can be distinguished by the presence of an outer ring of pistillate ray florets. The condition is controlled by a locus with two alleles (Trow, 1912). Because of incomplete dominance Hull (1974) introduced the allele symbols $T r$ and $T n$. Radiate and non-radiate plants are homozygous for $T r T r$ and $T n T n$, respectively; the heterozygote possesses only short ray florets.

The species used to be considered highly inbred, with reproduction verging on complete autogamy (Gibbs et al., 1975), but in experimental plots Campbell and Abbott (1976) found an average outcrossing rate of 22.4 per cent in nonradiate lines. Furthermore, Marshall and Abbott (1982, 1984a), using the ray floret locus as a marker, showed that in populations polymorphic for capitulum type, the radiate morph had a greater "female" outcrossing frequency than the nonradiate morph. This difference varied greatly between years and locations, with an observed maximum of 35 per cent more "female" outcrossing in the radiate plants. In a population from Leeds, higher outcrossing rates of ray florets within radiate capitula were sufficient to explain the difference. Marshall and Abbott $(1984 b)$ stated that functional protogyny in the radiate morph (Burtt, 1977) was partly responsible for its greater outcrossing rate, and proposed two further properties of the radiate condition which might contribute to this: (a) increased insect attraction by the radiate morph (but only if insects move more frequently from non-radiates to radiates than vice-versa); (b) possible cryptic self-incompatibility associated with the radiate condition. Here we show that there is indeed a self-incompatibility system present in the ray florets of some radiate plants. In addition, a second, unrelated system has been found which appears to retard the growth of self, relative to cross, pollen tubes in the disc florets of both radiate and non-radiate morphs.

\section{MATERIALS AND METHODS}

\section{Self-incompatibility in ray florets}

It is relatively easy to emasculate a capitulum of radiate $S$. vulgaris by removing the central hermaphrodite disc florets before their anthers are mature. This leaves a peripheral ring of virgin stigmas in the ray florets. These stigmas are convenient structures with which to study differential pollen germination because different pollen samples can be applied to each of the two stigmatic lobes.

During October 1985 bulk seed was collected from large polymorphic wasteland populations at Wath-on-Dearne, South Yorkshire (National Grid reference SK 442997), Edinburgh (NT 261735) and York (SE 605508). At each site single capitula 
were removed from each of 20 randomly sampled plants per morph. After germination the seedlings were grown under a 12 hour light regime in a glasshouse. In January 1986, 20 2-month-old radiate plants, which had just started to flower, were selected from each of the three population samples. For each plant about 20 self pollen grains were applied to one of the stigmatic lobes, and the same quantity of cross pollen placed on the remaining lobe, using a single short hair glued to a pin. Stigmatic lobes were marked with black ink, applied using a broken micro electrode as a fine pen, to identify pollen samples. Reciprocal marking confirmed that the presence of ink on the tips of stigma lobes has no effect on pollen germination. This procedure was carried out in at least five virgin ray florets per capitulum. After 24 hours stigmas were either fixed and stained for 10 minutes in cotton blue according to the method of Kho and Baer (1968) and viewed with a UV fluorescence microscope, or fixed, stained in cotton blue for only 90 seconds (D'Souza, 1972), mounted in glycerol and observed using a standard light microscope. In tandem with the above, the same plants were selfed and crossed in separated capitula by rubbing pairs of unemasculated capitula together; the plants were then placed in insect-proof cages. Cross pollen came from spare capitula on radiate experimental plants which originated from the same population. After $2 \frac{1}{2}$ weeks each capitulum was dissected open and the number of rayed florets which had set seed scored.

\section{Inhibition of self pollen germination in disc florets}

A series of experiments was designed to investigate possible self-incompatibility expressed within the stigmas of disc florets of both radiate and nonradiate morphs. The experiments gave information on the short-term germination success of self and cross pollen.

It proved impossible to emasculate disc florets satisfactorily without damaging their stigmas or effecting pollination, although others have successfully done so (Gibbs, 1971; Ingram et al., 1980). Pollination therefore took the form of rubbing together two unemasculated capitula. Pollen donating capitula were removed from one of three possible sources: (1) the test plant itself (selfpollination); (2) a plant from the same morph and population as the test plant (crossed, within-morph pollination); (3) a plant from the other morph but same population as the test plant (crossed, between-morphs pollination).
Forty plants of a specific morph were equally divided into two groups. In one group all 20 plants were selfed in one capitulum and crossed withinmorph in another. Plants in the other group were selfed in one capitulum but crossed betweenmorphs in another. This procedure was repeated for both morphs from two populations (Wath-onDearne and Edinburgh) and also for two time periods between pollination and fixation of the stigmas ( 24 and 48 hours); a total of 16 different treatments. After the allotted time of pollen growth, 20 stigmas per capitulum were removed at random, fixed and stained using the non-fluorescence method. The number of pollen grains that remained adhering to stigmas after both selfed and crossed pollinations was recorded. Plants were grown simultaneously under the same conditions and used at the same stage of flowering as in the first experiments.

\section{Frequencies of cross-progeny}

A set of experiments was designed to investigate whether the inhibition of self-pollen observed in the previous experiment produces measurable effects on the frequency of cross-progeny among offspring of radiate and non-radiate plants.

The ray-floret locus itself has been used as a marker to measure inter-morph outcrossing rates in S. vulgaris (Campbell and Abbott, 1976; Marshall and Abbott, 1982, 1984a). Without the existence of another, unlinked marker locus it is impossible to estimate intra-morph outcrossing rates. A suitable marker locus was found in radiate plants from York. The alleles are designated $B G$ (black capitulum bracts) and $B g$ (green bracts); black is dominant to green and the $B$-locus is unlinked to that controlling capitulum morph (Warren, unpublished). A simple breeding programme was used to produce green bracts in both morphs, and to produce bulk seed samples.

One hundred York plants of both radiate and non-radiate morphs, all with green bracts, were grown under glass in July 1986. One hundred homozygous black-bract plants of each capitulum morph were also grown as pollen donors. On flowering, the green-bract radiate plants were placed in insect-proof cages so that only selfing would occur. On fruiting these plants were separated into ray floret self-compatible and self-incompatible groups as in the first experiments. At this stage, 20 plants were selected from each of the three categories: (1) non-radiate; (2) radiate with self-compatible ray florets; (3) radiate with selfincompatible ray florets. Each plant, in all three 
groups of 20, was then crossed in two separate capitula. Crossing in one capitulum was withinmorph for the ray-floret locus and used the bractcolour locus as the marker:

\section{$T n T n / B g B g \times T n T n / B G B G$}

and

\section{$\operatorname{Tr} \operatorname{Tr} / B g B g \times \operatorname{Tr} \operatorname{Tr} / B G B G$}

The other capitulum was crossed between capitulum morphs allowing both the ray-floret and the bract loci to be used as markers for estimates of outcrossing:

$$
\operatorname{Tn} \operatorname{Tn} / B g B g \times \operatorname{Tr} T r / B G B G
$$

and

\section{$\operatorname{Tr} \operatorname{Tr} / B g B g \times \operatorname{Tn} T n / B G B G$.}

Crossing was achieved by rubbing together unemasculated capitula, a procedure which was repeated daily for 3 days to ensure all florets were receptive when exposed to cross pollen. The capitula were labelled and allowed to set seed. The outer seeds of radiate capitula, which are produced from ray florets, were collected separately (Marshall and Abbott, 1984b). This procedure can be carried out with total accuracy if the seeds are collected just as they become ripe, when the old corolla tube is still attached. All seeds were collected and stored at room temperature until sowing in December 1986. The progeny were grown in seed trays and scored for capitulum type and bract colour.

\section{RESULTS}

\section{Self-incompatibility in ray florets}

Using the fluorescence staining method, which involved only few changes of solutions, all pollen samples were seen to germinate but, surprisingly, pollen tube penetration of the stigmatic surface was not observed. The non-fluorescence staining method showed that, although both self and cross pollen grains appeared to have germinated, in one subset of plants only cross pollen remained on the stigmatic surface after passing through the staining procedure, which involves much washing and destaining (fig. 1a). These same plants, when selfed and placed in insect-proof cages, were found to set no seed in their ray florets, but did when crossed. In the other subset of plants, both self and outcross pollen grains germinated and adhered to the stigma equally (fig. 1b). These plants set
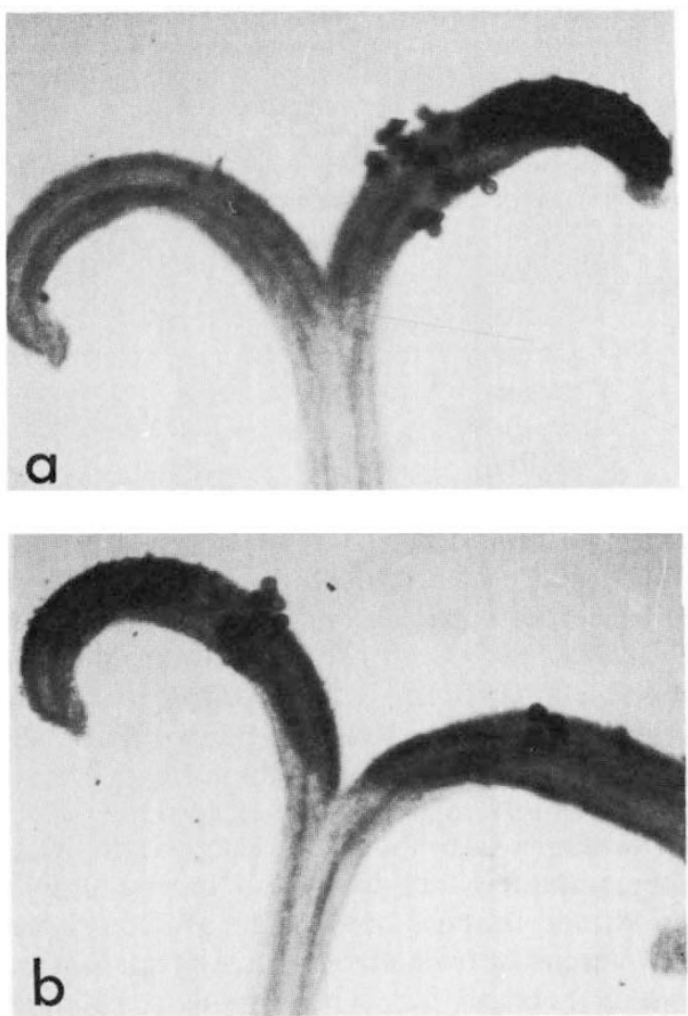

Figure 1 On each stigma cross pollen was applied to one lobe (marked) and self pollen to the other. (a) A self-incompatible ray floret stigma. (b) A self-compatible ray floret stigma.

seed in all florets when selfed and crossed. For each plant, irrespective of origin, there was perfect concordance between these two experimental approaches (table 1).

\section{Inhibition of self pollen germination in disc florets}

For each plant the mean number of pollen grains was calculated for the 20 stigmas examined from each of the selfed and crossed capitula. These values for the 20 plants in each treatment were compared by paired-sample $t$-tests (table 2). Comparisons are only valid between pairs of cross- and self-pollinations because different batches of plants were used for the two periods of pollen growth.

It is clear that after 24 hours on disc stigmas of both morphs cross pollen, irrespective of source, germinated in greater quantities than did self pollen. This difference was no longer apparent after 48 hours. 
Table 1 Number of plants observed with self-pollen adhering or not adhering to ray floret stigmas 24 hours after pollination. All plants in the first column, but none in the second, were observed to set seed in ray florets when selfed

\begin{tabular}{lll}
\hline Population & $\begin{array}{l}\text { Self-pollen } \\
\text { adhering }\end{array}$ & $\begin{array}{l}\text { Self-pollen } \\
\text { not adhering }\end{array}$ \\
\hline Wath-on-Dearne & 15 & 5 \\
Edinburgh & 10 & 10 \\
York & 7 & 13 \\
\hline
\end{tabular}

\section{Frequencies of cross-progeny}

All seed was grown to flowering and the crossing frequency calculated as the percentage of heterozygotes; $\operatorname{Tr} T n / B G B g$ for between-morph crosses and either $\operatorname{Tr} T r / B G B g$ or $T n T n / B G B g$ for withinmorph crosses. Less than one per cent of seed failed to produce a flowering plant. Mean crossing frequencies and ranges are given in table 3.

The results show that radiate plants which have self-incompatible ray florets do indeed only set crossed seed in these florets. The average percentage outcrossing from all other treatments was very similar, about 45 per cent, although the ranges were very wide.

\section{DISCUSSION}

These experiments have shown that $S$. vulgaris possesses two independent systems which inhibit the germination of self pollen. First, a proportion of radiate plants exhibits a true self-incompatibility system in their ray florets. Secondly, both morphs show retarded germination of self pollen, compared to cross pollen, on the stigmas of disc florets.

In plants with self-incompatible ray florets, self pollen appears to germinate when observed using the fluorescence staining method, but pollen tube growth must be blocked at the stigma surface as grains wash off during non-fluorescence staining. In the final experiment (table 3 ) these florets only set seed after crossing. It is possible that the selfincompatibility polymorphism in ray florets of $S$. vulgaris originated via introgression from Oxford Ragwort (Senecio squalidus L.), a closely related, radiate and obligate self-incompatible species. Hybridisation with $S$. squalidus is thought to be responsible for the origin of the radiate allele in S. vulgaris (Ingram, 1977; Ingram et al., 1980). Incompatibility in $S$. squalidus is, however, a feature of both ray and disc florets (Gibbs et al., 1975), which prompts the question: why should a self-incompatibility dimorphism in $S$. vulgaris be restricted only to the ray florets? Although unusual,

Table 2 Pollen germination on crossed and selfed stigmas in disc florets of $S$. vulgaris

\begin{tabular}{|c|c|c|c|c|c|}
\hline \multirow{2}{*}{$\begin{array}{l}\text { Time allowed } \\
\text { for pollen } \\
\text { germination }\end{array}$} & \multirow[b]{2}{*}{ Population } & \multirow[b]{2}{*}{ Morph $\dagger$} & \multirow[b]{2}{*}{ Sig.* } & \multicolumn{2}{|c|}{$\begin{array}{l}\text { Mean number of pollen } \\
\text { grains per stigma. }\end{array}$} \\
\hline & & & & Crossed & Selfed \\
\hline \multicolumn{6}{|c|}{ (a) Crossing within-morph } \\
\hline \multirow[t]{4}{*}{24 hours } & \multirow[t]{2}{*}{ Edinburgh } & NR & $p<0.001$ & $13 \cdot 3$ & $2 \cdot 8$ \\
\hline & & $\mathbf{R}$ & $p<0.001$ & $4 \cdot 3$ & $1 \cdot 4$ \\
\hline & \multirow[t]{2}{*}{ Wath-on-Dearne } & NR & $p<0.001$ & $7 \cdot 4$ & $2 \cdot 3$ \\
\hline & & $\mathbf{R}$ & $0.01>p>0.001$ & $9 \cdot 5$ & $4 \cdot 7$ \\
\hline \multirow[t]{4}{*}{48 hours } & \multirow[t]{2}{*}{ Edinburgh } & NR & N.S. & $4 \cdot 2$ & $3 \cdot 1$ \\
\hline & & $\mathrm{R}$ & N.S. & $8 \cdot 1$ & $7 \cdot 3$ \\
\hline & \multirow[t]{2}{*}{ Wath-on-Dearne } & NR & N.S. & $5 \cdot 3$ & $5 \cdot 1$ \\
\hline & & $\mathrm{R}$ & N.S. & $3 \cdot 1$ & $3 \cdot 0$ \\
\hline \multicolumn{6}{|c|}{ (b) Crossing between-morph } \\
\hline \multirow[t]{4}{*}{24 hours } & \multirow[t]{2}{*}{ Edinburgh } & NR & $p<0.001$ & 21.9 & $2 \cdot 3$ \\
\hline & & $\mathrm{R}$ & $p<0.001$ & $9 \cdot 4$ & $2 \cdot 1$ \\
\hline & \multirow[t]{2}{*}{ Wath-on-Dearne } & NR & $p<0.001$ & $5 \cdot 3$ & $3 \cdot 1$ \\
\hline & & $\mathrm{R}$ & $0.01>p>0.001$ & $9 \cdot 7$ & $4 \cdot 8$ \\
\hline \multirow[t]{4}{*}{48 hours } & \multirow[t]{2}{*}{ Edinburgh } & NR & N.S. & $21 \cdot 1$ & $24 \cdot 1$ \\
\hline & & $\mathrm{R}$ & N.S. & $11 \cdot 9$ & $10 \cdot 0$ \\
\hline & \multirow{2}{*}{ Wath-on-Dearne } & NR & N.S. & $7 \cdot 5$ & $8 \cdot 5$ \\
\hline & & $\mathrm{R}$ & N.S. & $14 \cdot 9$ & $14 \cdot 3$ \\
\hline
\end{tabular}

\footnotetext{
* Paired sample $t$-test comparisons of the mean numbers of germinating pollen grains per disc stigma in both selfed and crossed capitula.

$\dagger \mathrm{NR}=$ non-radiate, $\mathrm{R}=$ radiate.
} 
Table 3 Crossing frequencies, as scored by progeny

\begin{tabular}{|c|c|c|c|c|}
\hline Female parent* & $\begin{array}{l}\text { Within-morph crosses } \\
\text { Crossing } \\
\text { frequency }(\%)\end{array}$ & Range & $\begin{array}{l}\text { Between-morph crosses } \\
\text { Crossing } \\
\text { frequency }(\%)\end{array}$ & Range \\
\hline NR & $47 \cdot 7(616)$ & $8 \cdot 8-100$ & $44 \cdot 4(624)$ & $6 \cdot 3-92 \cdot 3$ \\
\hline \multicolumn{5}{|l|}{$\mathrm{R}(\mathrm{SC})$} \\
\hline (a) Disc seed & $44 \cdot 8(512)$ & $24 \cdot 2-63 \cdot 6$ & $53 \cdot 8(484)$ & $10 \cdot 4-100$ \\
\hline (b) Ray seed & $40 \cdot 0(133)$ & $0-81 \cdot 3$ & $54 \cdot 2(149)$ & $21 \cdot 1-92 \cdot 2$ \\
\hline \multicolumn{5}{|l|}{$\mathrm{R}(\mathrm{SI})$} \\
\hline (a) Disc seed & $43 \cdot 6(493)$ & $25 \cdot 8-71 \cdot 0$ & $45 \cdot 1(514)$ & $0-100$ \\
\hline (b) Ray seed & 100 & - & 100 & - \\
\hline
\end{tabular}

Crossing frequencies are mean values based upon total progeny scored per treatment. The number of progeny is given in parentheses.

* NR = non-radiate parent plant, $\mathrm{R}(\mathrm{SC})=$ radiate parent plant with self-compatible ray florets, $\mathrm{R}(\mathrm{SI})=\mathrm{radiate}$ parent plant with self-incompatible ray florets.

similar systems are found in other plants. For example, different pollen compatibility types are known even from within single flowers of tristylous self-incompatible species such as purple loosestrife, Lythrum salicaria L. (Darwin, 1877). Furthermore, ray-floret stigmas in $S$. squalidus and $S$. vulgaris are structurally different from disc-floret stigmas. The tips of disc-floret stigmas possess tufts of papillae (Proctor and Yeo, 1973) which are not found on ray-floret stigmas (Warren, personal observation), although these structures may be related to pollen presentation and not to selfincompatibility per se.

The discovery of a self-incompatibility polymorphism within stigmas of ray florets may, in part, explain the greater amount of inter-morph outcrossing shown by radiate plants in natural populations (Marshall and Abbott, 1982, 1984a). Different frequencies of "compatible" and "incompatible" radiate plants could also be responsible in part for observed differences between populations in levels of inter-morph outcrossing. In this respect, it should be pointed out that the numbers of each morph in table 1 may not reflect their frequencies in the source population because seed was collected from a small number of parents and subsequently bulked.

The inhibition of self pollen, which occurs within the disc florets of both radiate and nonradiate $S$. vulgaris, is similar to the cryptic selfincompatibility found in the wallflower, Cheiranthus cheiri L. (Bateman, 1956) and in Amsinckia grandiflora Kleeb. (Weller and Ornduff, 1977). Table 2 shows that self pollen is slower to germinate than cross pollen; generally, fewer self pollen grains adhere to stigmas after 24 hours than to those left for 48 hours before fixation. The results using cross pollen are similar irrespective of pater- nal morph. Both self and cross pollen samples came only from within the experiment. Because each plant was selfed, and also provided pollen for one cross chosen at random, the differences found between selfs and crosses at 24 hours (table 2) will not reflect defective pollen from any one plant. When cross pollinated (table 3 ), a vast range of crossing frequencies was observed in all treatments, showing a high potential for outbreeding; similar ranges were reported from open-pollinated plots by Campbell and Abbott (1976). Since self pollen was already present upon stigmas before crossing occurred, it is remarkable to find that some capitula set 100 per cent crossed seeds. This result in itself suggests cross pollen has an advantage over self pollen. The mean crossing levels recorded in table 3 are close to the 50 per cent found by Richards (1975) using the ray-floret locus as marker and the same means of cross pollination. The presence of self pollen will, of course, in the absence of cross pollen, allow 100 per cent selfing of disc florets.

Why should cryptic self-incompatibility have evolved in disc florets? One possible explanation is that in selfing species in which the stigma also serves as the pollen presenting organ, as it does in $S$. vulgaris, selection may act to favour a mechanism in which initially only a small amount of self pollen germinates. Even after 48 hours, at most only about 40 pollen grains per stigma were ever seen to germinate. If no such system existed, all self pollen would immediately germinate on the stigma. In S. vulgaris, which produces about 200 pollen grains per floret (Gibbs et al., 1975), the stigma might be mechanically damaged if this happened. If all self pollen grains did germinate, outbreeding might be reduced because (a) the pollen is no longer free for transport to other plants and 
(b) the stigmatic surface is blocked to incoming pollen. A second explanation might be that this system is a relic of an incompatibility mechanism retained from a radiate, self-incompatible ancestor (Kadereit, 1984). The system could have broken down as a result of selection for inbreeding. As the stage was approached at which 100 per cent selfing was ensured selection would be relaxed, leaving some residual incompatibility.

The observation that only a small proportion of self pollen ever appears to germinate raises a number of questions. For example, what controls which self pollen grains germinate, what controls the number of pollen grains which germinate, and are the non-germinating pollen grains viable? Before we can understand the implications of these results, we need to have more accurate measures of inter- and intra-morph outcrossing rates in natural populations.

$S$. vulgaris has long been regarded as an inbreeder (Haskell, 1953). The demonstration of pollen inhibition and self-incompatibility systems within this species should cause us to look more closely at other species traditionally considered to be inbreeders.

Acknowledgements We would like to thank Dr R. J. Abbott for his many constructive comments. The support of a N.E.R.C. research studentship to J.M.W. is gratefully acknowledged.

\section{REFERENCES}

BATEMAN, A. J. 1956. Cryptic self-incompatibility in the wallflower Cheiranthus cheiri L. Heredity, 10, 257-261.

BURTT, B. L. 1977. Aspects of diversification of the capitulum. In Heywood et al. (eds.) The Biology and Chemistry of the Compositae, Vol 1, Academic Press, London, pp. 41-59.
CAMPBELL, J. M. AND ABBOTT, R. J. 1976. Variability of outcrossing frequency in Senecio vulgaris. Heredity, 36, $267-$ 274.

DARWIN, C. 1877. The Different Forms of Flowers on Plants of the Same Species, 2nd ed. John Murray, London.

D'SOUZA, L. 1972. Staining pollen tubes in the styles of cereals with cotton blue. Stain Technol. 47, 107-108.

GIBBS, P. E. 1971. Studies on synthetic hybrids of British species of Senecio, 1. Senecio viscosus L. $\times S$. vulgaris L. Trans. bot. Soc. Edinb., 41, 213-218.

GibBS, P. E., MilNe, C. AND VARGas CARrillo, M. V. 1975. Correlation between the breeding systems and recombination index in five species of Senecio. New Phytol, 75, 619-626.

HASkell, G. 1953. Adaptation and the breeding system in groundsel. Genetica, 26, 468-484.

HULL, P. 1974. Self fertilisation and the distribution of the radiate form of Senecio vulgaris L. in Central Scotland. Watsonia, 10, 69-75.

INGRAM, R. 1977. Synthesis of the hybrid Senecio squalidus L. $\times S$. vulgaris L. f. radiatus Hegi. Heredity, 39, 171-173.

INGRAM, R., WEIR, J. AND ABBOTT, R. J. 1980. New evidence concerning the origin of inland radiate groundsel, Senecio vulgaris L. var hibernicus Syme. New Phytol. 84, 543-546.

KADEREIT, J. W. 1984. The origin of Senecio vulgaris L. (Asteraceae). Pl. Syst. Evol, , 145, 135-155.

KHO, Y. O. AND BAER, J. 1968. Observing pollen tubes by means of fluorescence. Euphytica, 17, 298-302.

MARSHALL, D. F. AND ABBOTT, R. J. 1982. Polymorphism for outcrossing frequency at the ray floret locus in Senecio vulgaris L. I. Evidence. Heredity, 48, 227-235.

MARSHALL, D. F. AND ABBOTT, R. J. 1984a. Polymorphism for outcrossing frequency at the ray floret locus in Senecio vulgaris L. II. Confirmation. Heredity, 52, 331-336.

MARSHALL, D. F. AND ABBOTT, R. J. 1984b. Polymorphism for outcrossing frequency at the ray floret locus in Senecio vulgaris L. III. Causes. Heredity, 53, 145-149.

PROCTOR, M. AND YEO, P. 1973. The Pollination of Flowers. Collins, London.

RICHARDS, A. J. 1975. The inheritance and behaviour of the rayed gene complex in Senecio vulgaris. Heredity, 34, $95-$ 104.

TROW, A. H. 1912. On the inheritance of certain characters in the common groundsel-Senecio vulgaris, Linn.-and its segregates. J. Genet., 2, 239-276.

WELLER, S. G. AND ORNDUFF, R. 1977. Cryptic self-incompatibility in Amsinckia grandiflora Kleeb. Evolution, 31, 47-51. 